\title{
A Study on Molecular Mechanisms of Adiposis Induced by Long-Term Treatment of High-Fat and High-Sucrose in C57BL/6J Mice
}

\author{
Xiaodan LI ${ }^{1}$, Peipei TU ${ }^{2}$, Muhammad UMAR ${ }^{1}$, Qiqi LIU ${ }^{1}$, Wenya LUO ${ }^{1}$, Xingkai YANG ${ }^{1}$, \\ Jianghong $\mathrm{ZHU}^{2}$, Deling KONG ${ }^{1}$, Minggang LI ${ }^{1}$
}

${ }^{1}$ State Key Laboratory of Medical Chemical Biology, Key Laboratory for Bioactive Materials of the Ministry of Education, College of Life Science, Nankai University, Tianjin, China, ${ }^{2}$ College of Life Science, Anhui Medical University, Hefei, China

Received December 4, 2017

Accepted July 10, 2018

Epub Ahead of Print October 23, 2018

\begin{abstract}
Summary
Adiposis is reputed as a twin disease of type 2 diabetes and greatly harmful to human health. In order to understand the molecular mechanisms of adiposis, the changes of physiological, pathological, epigenetic and correlative gene expression were investigated during the adiposis development of C57BL/6] mice induced by long time ( 9 months) high-fat and high-sucrose diet (HFSD) sustainably. The results showed that mRNA transcription level of the Leptin, G/ut4 and G/ut2 genes have been obviously changed, which exhibit a negative correlation with methylation on their promoter DNA. The results also revealed that HFSD induced higher level of DNA methyltransferase 1 (DNMT1) in fat tissue might play important role in regulating the changes of methylation pattern on G/ut4 and Leptin genes, and which might be one of the molecular mechanisms for the adiposis development.
\end{abstract}

\section{Key words}

Obesity • Dietary • Epigenetic • DNA methylation • DNMT1

\section{Corresponding author}

M. Li, Life Science College, Nankai University, Weijin Road 94, Nankai District, 300071, Tianjin, China. Fax: +86/22/23504582. E-mail: mgl@nankai.edu.cn

\section{Introduction}

The worldwide epidemic of obesity has been regarded as one of the most threatening factors to public health. From the data of World Health Organization
(WHO) in 2014, there are more than 1.9 billion adults overweight, moreover, of those more than half a billion are believed to be obese status. Adiposis, also known as adiposity, is characterized by the accumulation of fatty tissue. There was a higher prevalence of cardiovascular disease (Lim et al. 2012), type 2 diabetes (Isomaa et al. 2001), nonalcoholic fatty liver (Starley et al. 2010) and even some kinds of cancer (Buschemeyer and Freedland 2007, Iwase et al. 2016) caused by adiposis.

There are several potential contributing factors of obesity, including environment, genetics and decreasing of physical activity (Malik et al. 2013). As we all know, food is the energy source for human body, which could be digested into amino acids, fatty acids and monose (mainly glucose). Normally, postprandial hyperglycemia is regulated by insulin for providing energy or stored as glycogen in both liver and muscle. In this regard, liver as the most important organ of glucose metabolic, always response to the hyperinsulinemia through Insr, and maintain glucose homeostasis through Gck and Glut2. Besides, liver will increase gluconeogenesis to answer the hypoglycemia, which involved with the $\mathrm{Pgcl}$ regulation. As one of target organs of insulin, adipose tissue could transport glucose by Glut4, which also was induced by Pgcl. However, the chronic hyperglycemia result in the accumulation of fat and even hyperinsulinemia because of a long-term excessive intake of carbohydrates. Furthermore, the chronic hyperinsulinemia of circulation decreases the sensitivity of peripheral tissues to insulin and even cause 
insulin resistance. The insulin resistance stage result in increasing insulin release of pancreas $\beta$ cells, which in turn aggravate the situation of insulin resistance (Bastard et al. 2006).

One of the most closely related to metabolic risk factors among fat accumulation is the excess of abdominal fat, which is mainly distributed in subcutaneous and visceral. Compare to the subcutaneous adipose, the visceral fat show high risk for the development of metabolic syndrome, because of multiple products secreted from them, such as leptin, adiponectin, inflammatory cytokines and so forth (James et al. 2004). As for leptin, which is mainly expressed in adipose tissue and plays an important role in regulation of energy metabolism by inhibiting appetite and food intake and stimulating the energy expenditure (Friedman and Halaas 1998). For human with leptin deficiency and certain obese rodents, leptin treatment is able to effectively cut down food intake and bodyweight (Ramachandrappa and Farooqi 2011). However, this treatment is completely invalid in diet-induced obese mice (Halaas et al. 1997), which is defined as leptin resistance for the state of obesity with hyperleptinaemia and/or a reduction reaction to leptin treatment. Moreover, leptin resistance take part in the pathogenic development of diet-induced obesity, which mainly attribute to excess fat by high-fat diet (Scarpace et al. 2005). Besides, research has proved that fat content within the high-fat diet is not the only factor for leptin resistance (Liu et al. 2011), the different nutritional aspects may also play a critical role. At this point, sugars and fats content show different leptin sensitivity, fat-diet is easier induced to leptin resistance comparing to sugar-diet (Haring and Harris 2011). In addition, the inflammatory cytokines like IL-6, TNF $\alpha$ are also increased in obese individuals, the increase of cytokines synthesized from fat tissue may affect the suppression action of insulin in lipolysis in this sense, it probably represents the insulin resistance state in adipose tissue, perhaps in other tissues, muscle and liver (Shulman 2000, Ridker and Morrow 2003). All of these physiological changes are probably traceable to the dynamic changes in gene expression patterns. Therefore, the diet-induced obesity is probably the result of gene expression change. However, it is still not elucidated how the dietary changes induced changes of gene expression patterns.

Recently, epigenetics has been getting a lot of attention as one kind of molecular mechanisms mediating metabolic diseases. It is generally known that evidences from human and rodent have demonstrated maternal nutrition contribute to a particular epigenotype and thus it will produce developmental metabolic difference in offspring (Lavebratt et al. 2012). Moreover, these kinds of epigenetic landscape are also susceptible to the environment (like dietary) in childhood and adult (McGowan et al. 2009). The epigenome-wide association studies (EWAS) which differentially methylated $\mathrm{CpG}$ sites relate to obesity, are likely to explicate the causes of diet-induced obesity. Our previous studies have shown that histone modification was involved in regulating the development of type 2 diabetes (T2D), especially, the total histone $\mathrm{H} 3 \mathrm{~K} 4$ monomethylation, $\mathrm{H} 3 \mathrm{~K} 9$ dimethylation and $\mathrm{H} 3 \mathrm{~K} 9 / \mathrm{H} 3 \mathrm{~K} 23$ acetylation of liver, and histone modification also associates with dietinduced obesity or early stage of T2D mice (Tu et al. 2015). In this sense, DNA methylation of associated genes perhaps play a vital role in genes and environment interactions (Xu et al. 2013).

Several researches have proved that DNA methylation of gene promoter region was concerned with diet-induced obesity or T2D, including Leptin and Pgcla (Mello et al. 2014). However, the most researches focus on the methylation changes of related genes in offspring under maternal nutritional imbalances, or the changes of diet-induced obesity after a short time (Lillycrop et al. 2008, Seki et al. 2012), the mechanisms of adiposis in a sustainable long term HFSD induction are still remained unclear yet. To clarify that, the obesity progress of mice induced by sustainable long time HFSD was monitored through measuring the physiological biochemical indexes, HE staining, DNMT1 gene expression, promoter DNA methylation pattern in present study. These findings may conduce to further understand the molecular mechanisms of adiposis development.

\section{Methods}

\section{Animals and treatments}

C57BL/6J male mice (3 weeks old), weighing 10 to $12 \mathrm{~g}$, were purchased from Laboratory Animal Center of the Academy of Military Medical Sciences of China (Animal License Number: SCXK-2007-004, Beijing, China). They were maintained in $12 \mathrm{~h}$ light/dark cycles with unlimited access to food and water in a temperature of $23 \pm 1{ }^{\circ} \mathrm{C}$ and a humidity of $60 \pm 5 \%$ controlled room. After one week of acclimation, mice were randomly divided into two groups ( $\mathrm{n}=10$ per cage): control group, $\mathrm{n}=30$, were feed control $(\mathrm{CON})$ dietary; 
experimental group, $\mathrm{n}=30$, were given a high-fat and high-sucrose diet (HFSD) respectively for nine months (Table 1). They were allowed to access to chow and water freely. The food intake was recorded every 3 days, and the body weights were assessed once a week. After the weighing, mice were fasted for seven hours, and then measuring FBG (fasting blood glucose) by a blood glucose meter (Johnson, New Brunswick, USA) once a week. During treatment processing, blood was collected from orbit for later analysis, liver and epididymal fat pad were partly used to carry out the HE-staining and the rest were employed to extract the genome DNA, total mRNA and total protein at different time points, containing third-, fifth- and ninth-month respectively. All procedures performed in this study involving animals were in accordance with the guidelines of the Chinese Council on Animal Care as well as the University of Nankai Animal Care Committee.

Table 1. Composition of mice diets.

\begin{tabular}{lcc}
\hline Composition & CON $(/ \mathbf{1 0 0} \mathbf{g})$ & HFSD (/100 g) \\
\hline Energy & $539 \mathrm{~kJ}$ & $1,512.45 \mathrm{~kJ}$ \\
Fat & $4 \mathrm{~g}$ & $22.2 \mathrm{~g}$ \\
Protein & $18 \mathrm{~g}$ & $16.9 \mathrm{~g}$ \\
Carbohydrates & $5 \mathrm{~g}$ & $23.75 \mathrm{~g}$ \\
$\quad$ Sucrose & 0 & $21.5 \mathrm{~g}$ \\
Vitamins & $134.3 \mathrm{mg}$ & $134.3 \mathrm{mg}$ \\
Calcium & $1.8 \mathrm{~g}$ & $1.8 \mathrm{~g}$ \\
Mineral substance & $0.9 \mathrm{~g}$ & $0.9 \mathrm{~g}$ \\
Micronutrients & $21.6 \mathrm{mg}$ & $21.6 \mathrm{mg}$ \\
\hline
\end{tabular}

Note: Basic diets, GB14924.3 (National Standards of the People's Republic of China).

\section{Measurement obesity parameters}

The body length of mice was measured (from apex nasi to anus) after sodium pentobarbital treatment at every independent experiment. Lee's index (Bernardis and Patterson 1968) was used to assess the obese mice model, and it was calculated by formulation: Lee's index $=[\text { Body weight }(\mathrm{g})]^{1 / 3} \times 10^{3} /$ Body length $(\mathrm{cm})$. Further evidence for obese mice came from fat coefficient (fat/body mass, \%). Briefly, the fat tissues extracted from mesentery, epididymis and perirenal, and was then dried by filter paper before weighing.

Measurements of serum and oral glucose tolerance testing

Insulin, leptin level was determined by Mouse Insulin (INS) ELISA Kit (Dingguo, Tianjin, China) and Murine Leptin ELISA Kit (ImmunoWay, Tennyson, USA) respectively. Glycosylated hemoglobin (GHbA1c), triglyceride (TG), cholesterol (CHO) were measured by using autobiochemical analyzer (HITACHI 7600, Japan) in Tianjin Medical University Metabolic Diseases Hospital (Tianjin, China). The homeostasis model analysis (HOMA), including HOMA- $\beta$ ( $\beta$ cell function),
HOMA-IS (insulin sensitivity) and HOMA-IR (insulin resistance) were calculated by the HOMA2 calculator, which could be used for evaluating the insulin secretion and insulin sensitivity (Wallace et al. 2004). Oral glucose tolerance testing (OGTT) was carried out before execution as described (Wolever et al. 1991). To be brief, mice were orally administrated with $2 \mathrm{~g} / \mathrm{kg}$ body weight of glucose dissolved in water $(40 \%, \mathrm{w} / \mathrm{v})$ after 12 -hour fasting. At 0, 30, 60 and $120 \mathrm{~min}$ after gavage, we measured blood glucose, and then plotted concentrationtime curve, calculated the area under the curve (AUC) by trapezoid method.

\section{Liver/fat tissue isolation and HE staining}

Liver/fat tissue was dissected and frozen in liquid nitrogen rapidly. Then, the tissues were transferred to $-80{ }^{\circ} \mathrm{C}$. There were 10 mice for each group to examine the HE-staining, and 3 images were examined per mouse, the extracted fresh tissue (similar region of liver and epididymal fat pad) was fixed in $10 \%$ buffered formalin, embedded in paraffin, serially sectioned and stained with hematoxylin eosin. Finally, there were 6 to 8 mice could reach the presented data, and the HE staining images we 
provided were the representative images. Liver and fat tissue histopathological grading were assessed using the scoring system proposed by previous researches (Brunt et al. 1999, Ip et al. 2014). The extent of inflammatory infiltration and steatosis in 10 different random fields were calculated by a blinded rater. The area ratio of muscle degeneration and fibrosis in 10 different random fields was analyzed by a blinded rater. The cross-sectional area of lipocytes (Chen and Farese 2002) in 10 different random fields were measured by ImagePro Plus Software. Genome DNA, total RNA and total protein were extracted by animal tissue/cell genome DNA extraction kit (Solarbio, Beijing, China), RNAiso reagent (Takara, Japan) and Total Protein Extraction Kit (BestBio, Shanghai, China) from liver and epididymal fat pad according to the manufacturer's instructions as described previously (Duan et al. 2016) respectively.

\section{Quantitative real-time $P C R$}

The total RNA $(0.8 \mu \mathrm{g})$ was used to synthesize first-strand cDNA with the Reverse Transcriptase M-MLV (RNase H-) and universal primers (Takara, Japan). And then the mRNA levels of genes expression were measured by quantitative real-time PCR with $12.5 \mu 1$ of SYBR Premix Ex Taq (2×, Takara, Japan), $20 \mathrm{ng}$ of cDNA, $10 \mu \mathrm{M}$ of each primer for each reaction mixture, which was carried out using a CFX ConnectTM Real-Time System (Bio-Rad, California, USA). The specific primers are listed in Table S1. PCR cycle conditions were $95^{\circ} \mathrm{C}$ for $5 \mathrm{~min}$, followed by 45 cycles of denaturation at $95^{\circ} \mathrm{C}$ for $15 \mathrm{~s}$ and annealing at $56{ }^{\circ} \mathrm{C}$ for $30 \mathrm{~s}$, and extension at $72{ }^{\circ} \mathrm{C}$ for $30 \mathrm{~s}$. Triple samples were analyzed for each gene, and glycerol-dehyde-3-phosphate dehydrogenase $(G A P D H)$ was used as an internal control. The expression level was evaluated by $2^{-\Delta \Delta \mathrm{Ct}}$ (Ginzinger 2002).

\section{Bisulfate sequencing PCR (BSP)}

Bisulfite conversion of genomic DNA was performed as previously described (Lewin et al. 2004). Briefly, $1 \mu \mathrm{g}$ of genomic DNA was modified using the CpGenomeTM Turbo Bisulfite Modification Kit (Millipore, Boston, USA) according to the manufacturer's instructions. Bisulfite converted DNA $(50 \mathrm{ng})$ was then employed as a template in semi-nested PCR amplification with the primers below (Table S1). For BSP, the Glut2 primer targets $4 \mathrm{CpG}$ sites, Leptin primer targets $18 \mathrm{CpG}$ sites, and Glut4 primer targets $11 \mathrm{CpG}$ sites respectively. The PCR products were sequenced directly, and DNA methylation ratio was calculated by measuring relative peak heights of cytosine (C) and thymine (T) peaks at each $\mathrm{CpG}$ site, and the methylation ratio was calculated as " $\mathrm{C}:(\mathrm{C}+\mathrm{T})$ ".

\section{Western blot}

The extracted total protein, $15 \mu \mathrm{g}$ was assayed by SDS-PAGE with $10 \%$ of separation gel. For western blot, the SDS-PAGE gel was transferred to a polyvinylidene difluoride membrane (DingGuo, Beijing, China) with the blocking buffer contained $0.2 \%$ Tween-20 and $5 \%$ skim milk powder, and then the membrane incubated with mouse anti-DNMT1 monoclonal antibody (Abcam, Cambridge, USA) (1:2,000 dilution) or $\beta$-actin (Abcam, Cambridge, USA) $(1: 3,000)$ for $2 \mathrm{~h}$ at $37^{\circ} \mathrm{C}$. The horseradish peroxidaseconjugated goat anti-mouse IgG (1:5,000 dilution) was used to detect protein-antibody complex, and then the ECL kit (Tiangen, Beijing, Chian) was used to carry out the chemiluminescence reaction.

\section{Statistical analysis}

All data is represented as mean $\pm \mathrm{SD}$. The significance between groups was compared by independent-samples Student's t-test. We used the chi-square test to evaluate the significant difference in methylation density between different groups. A probability level of $p<0.05$ was considered to indicate a significant difference.

\section{Results}

The effects of Sustainable HFSD on mice development

To determine the long time sustainable HFSD effect on $\mathrm{C} 57 \mathrm{BL} / 6 \mathrm{~J}$ mice development, the characteristics of mice were continuously tracked in different stage of HFSD treatments. The results were shown in Table 2 and Table 3. After three months' HFSD treatment, the HFSD group gained more body weight than the control group (Table 2), and the changes were more significant in the next six months. In addition, both Lee's index and fat/body mass (\%) of HFSD group were significantly increased compared to those of CON group after three months $(p<0.001)$, and also the significant difference remained to the ninth-month (Table 3). In keeping with this, the average daily calorie intake was increased than those of CON mice among three different periods $(p<0.05)$; nevertheless, the average daily water intake of HFSD mice was barely any different from those of CON 
mice $(p>0.05)$ (Table 2). Together, these results showed that the high-fat (fat, $22.2 \mathrm{~g} / 100 \mathrm{~g}$ ) and high-sucrose (sucrose, $21.5 \mathrm{~g} / 100 \mathrm{~g}$ ) dietary could remarkably induce the $\mathrm{C} 57 \mathrm{BL} / 6 \mathrm{~J}$ mice to adiposis.

Table 2. Characteristics changes after different diets treatment.

\begin{tabular}{lcccccc}
\hline & \multicolumn{2}{c}{ Third-month } & \multicolumn{2}{c}{ Fifth-month } & \multicolumn{2}{c}{ Ninth-month } \\
\cline { 2 - 7 } Program & CON & HFSD & CON & HFSD & CON & HFSD \\
\hline Body weight (g) & $25.81 \pm 1.17$ & $34.06 \pm 1.41^{* *}$ & $30.03 \pm 1.31$ & $43.85 \pm 1.77 * *$ & $30.89 \pm 1.09$ & $54.96 \pm 1.9^{* *}$ \\
Average calorie intake (kJ) & $15.04 \pm 0.16$ & $46.13 \pm 0.76^{*}$ & $15.09 \pm 0.43$ & $46.43 \pm 2.42^{*}$ & $15.90 \pm 0.38$ & $50.67 \pm 1.21^{*}$ \\
Average water intake (ml) & $3.62 \pm 0.11$ & $3.47 \pm 0.24$ & $3.37 \pm 0.12$ & $3.23 \pm 0.18$ & $3.44 \pm 0.07$ & $3.22 \pm 0.14$ \\
Leptin (ng/ml) & $8.55 \pm 1.31$ & $14.80 \pm 1.12^{*}$ & $9.10 \pm 1.13$ & $16.21 \pm 0.66^{*}$ & $10.07 \pm 0.77$ & $16.88 \pm 2.2^{*}$ \\
Cholesterol (mM) & $2.21 \pm 0.19$ & $4.97 \pm 0.20^{* *}$ & $2.23 \pm 0.17$ & $5.45 \pm 0.38^{*}$ & $2.41 \pm 0.16$ & $6.21 \pm 0.22^{* *}$ \\
Triglycerides (mM) & $1.43 \pm 0.11$ & $1.67 \pm 0.10$ & $1.53 \pm 0.14$ & $2.29 \pm 0.23^{*}$ & $1.60 \pm 0.19$ & $2.49 \pm 0.22^{*}$ \\
Fasting blood glucose (mM) & $4.92 \pm 0.26$ & $5.99 \pm 0.51^{* *}$ & $5.0 \pm 0.14$ & $10.12 \pm 0.6^{* *}$ & $5.04 \pm 0.19$ & $7.86 \pm 0.73^{* * *}$ \\
Insulin (mU/l) & $6.06 \pm 0.17$ & $6.22 \pm 0.32$ & $6.03 \pm 0.2$ & $6.74 \pm 0.51^{* *}$ & $6.03 \pm 0.21$ & $6.11 \pm 0.42$ \\
GHbA1c (\%) & $3.15 \pm 0.21$ & $3.63 \pm 0.25$ & $3.7 \pm 0.14$ & $4.1 \pm 0.5$ & $3.85 \pm 0.25$ & $4.9 \pm 0.5^{*}$ \\
OGTT-AUC (mM/min) & $419.5 \pm 71.38$ & $529.5 \pm 61.06$ & $428 \pm 42.57$ & $673 \pm 48.0^{* *}$ & $487.5 \pm 36.0$ & $560.5 \pm 47.3$ \\
Homeostasis model assessment $(H O M A)$ & & & & & \\
HOMA-IR & $0.78 \pm 0.04$ & $0.85 \pm 0.06$ & $0.78 \pm 0.04$ & $1.02 \pm 0.09^{*}$ & $0.79 \pm 0.04$ & $0.88 \pm 0.08$ \\
HOMA- $\beta$ (\%) & $83.97 \pm 7.36$ & $58.07 \pm 7.82^{*}$ & $80.73 \pm 2.75$ & $22.07 \pm 1.2 * *$ & $79.57 \pm 4.15$ & $33.6 \pm 4.51^{*}$ \\
HOMA-IS\% & $127.3 \pm 5.3$ & $118.43 \pm 8.36$ & $127.33 \pm 5.1$ & $98.03 \pm 8.56^{*}$ & $127.13 \pm 5.6$ & $113.77 \pm 9.96$ \\
\hline
\end{tabular}

CON, control diet group; HFSD, high-fat and -sucrose diet group. GHbA1c (\%), glycosylated hemoglobin; OGTT-AUC (mM/min), the oral glucose tolerance test (OGTT) was calculated by the area under the curve (AUC) at four different times $0,30,60$ and 120 min. HOMA-IR was used to evaluate the level of insulin resistance; HOMA- $\beta$ (\%) was used to evaluate $\beta$ cell functions; HOMA-IS\% was used to evaluate insulin sensitivity by HOMA2 calculator. There were 30 mice for CON group and 30 mice for HFSD group respectively; to be more specific, the total 30 mice of CON/HFSD group were also randomly divided into three groups ( $n=10$ per group), including three-, five- and nine-month treatment. $* p<0.05$ and $* * p<0.001$ vs. CON group at same age. ${ }^{\#} p<0.05$ vs. HFSD group following dietary treatment for five months. Values are presented as mean \pm S.E.M $(n=10)$.

Table 3. The Lee's index and fat coefficient (fat/body mass).

\begin{tabular}{lcccccc}
\hline \multirow{2}{*}{ Program } & \multicolumn{2}{c}{ Three-month } & \multicolumn{2}{c}{ Five-month } & \multicolumn{2}{c}{ Nine-month } \\
\cline { 2 - 7 } & CON & HFSD & CON & HFSD & CON & HFSD \\
\hline Body length $(\mathrm{cm})$ & $8.53 \pm 0.11$ & $8.91 \pm 0.17$ & $9.17 \pm 0.13$ & $9.30 \pm 0.17$ & $9.15 \pm 0.09$ & $9.50 \pm 0.21^{*}$ \\
Body weight $(\mathrm{g})$ & $25.81 \pm 1.17$ & $34.06 \pm 1.41^{* *}$ & $30.03 \pm 1.31$ & $43.85 \pm 1.77^{* *}$ & $30.89 \pm 1.09$ & $54.96 \pm 1.90^{* *}$ \\
Lee's index & $339.68 \pm 5.39$ & $366.27 \pm 6.01^{* *}$ & $341.57 \pm 5.37$ & $380.41 \pm 6.26^{* *}$ & $343.22 \pm 5.51$ & $399.78 \pm 7.78^{* *}$ \\
Dried fat weight $(\mathrm{g})$ & $0.39 \pm 0.05$ & $1.37 \pm 0.10^{* *}$ & $0.59 \pm 0.07$ & $2.11 \pm 0.06^{* *}$ & $0.56 \pm 0.05$ & $3.14 \pm 0.07^{* *}$ \\
Fat/body mass (\%) & $1.51 \pm 0.13$ & $4.02 \pm 0.70^{* *}$ & $1.96 \pm 0.19$ & $4.71 \pm 0.85^{* *}$ & $1.81 \pm 0.11$ & $5.70 \pm 0.93^{* *}$ \\
\hline
\end{tabular}

CON, control diet group; HFSD, high-fat and -sucrose diet group. Lee's index was calculated by formulation: Lee's index = [Body weight $(\mathrm{g})]^{1 / 3} \times 10^{3} /$ Body length $(\mathrm{cm})$ for valuing the obese mice model, and the (fat/body mass, \%) means fat coefficient providing further evidence for it. Values are presented as mean \pm S.E.M $(n=10)$. The P-values were calculated using Student's $\mathrm{t}$-test. $* p<0.05$, $* * p<0.001$ vs. CON group at same age.

The serum leptin concentration was evaluated at the end of every treatment period. Interestingly, the leptin level of HFSD groups were higher than those of CON groups during every period, and it presented an increased trend in HFSD groups with time (Table 2). By comparison with the gradual increased bodyweight and leptin levels, our data suggested that the HFSD mice showed leptin resistance with time. In consistent with the 
increasing obesity levels, the cholesterol and triglycerides concentration of HFSD groups were significantly increased compared to those of CON groups, furthermore, both of them had an increased tendency in HFSD group with time.

HFSD induced the impairments to the regulation of glucose homeostasis

The HFSD mice exhibited higher fasting blood glucose (Table 2), and reached the highest level at fifth month (HFSD: $10.12 \pm 0.60 \mathrm{mM}$; CON: $5.0 \pm 0.14 \mathrm{mM}$ ), but it was significantly decreased at ninth month (HFSD of ninth-month: $7.86 \pm 0.73 \mathrm{mM}$ ) in line with fasting insulin concentration. In addition, the level of glycosylated hemoglobin (GHbA1c) in HFSD groups had a gradually increased trend compare to those in CON groups, but there was no significant difference between them. Homeostasis model assessment (HOMA) of $\beta$ cell function is based on the fasting glucose and insulin concentrations (Table 2). The HOMA-IR, homeostasis model assessment of insulin resistance, showed significant insulin resistance in HFSD group (HFSD: 1.02 \pm 0.09 ; CON: 0.78 \pm 0.04 ) after five months' treatment. The $\beta$ cell function of $\mathrm{CON}$ group showed more powerful than HFSD group by the HOMA- $\beta(\%)$. The similarity also presented in HOMA-IS (\%, insulin sensitivity). As expected, HFSD treatments could partly decrease the glucose tolerance by oral glucose tolerance testing (OGTT) with no significant difference, especially during the five-month treatment. Briefly, the glucose level increased highly in HFSD mice compared with CON mice at all time-points (data not shown), and same result was presented by a reduced area under the curve (AUC, OGTT-AUC) after treatment, especially after

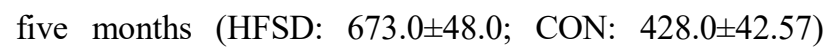
(Table 2). These results indicated that $\mathrm{C} 57 \mathrm{BL} / 6 \mathrm{~J}$ mice treated with HFSD (high-fat, $22.2 \mathrm{~g} / 100 \mathrm{~g}$, high-sucrose $21.5 \mathrm{~g} / 100 \mathrm{~g}$ diet) since five months have shown a stable adiposis symptom and an obviously characteristics of impaired glucose homeostasis.

\section{Pathophysiological analysis of liver and fat tissue from treated mice}

To determine the pathophysiological status in HFSD mice, hematoxylin-eosin staining (HE staining) of liver and fat tissue from treated mince was performed. The liver tissue HE staining results of HFSD mice showed varying degrees of pathologic morphology with three different periods (Fig. 1b1-b3 and Table 4) compared with CON mice (Fig. 1a1-a3).
The severity degree of pathological damage in HFSD mice was more significant with the time, and showed severe fatty liver and macrovesicular steatosis after nine months. Moreover, hepatic steatosis was found accompanied with the spotty necrosis, inflammatory cell infiltrating (Fig. 1b3). For fat tissue, the HE staining of HFSD mice represented significantly increased crosssectional area of lipocytes, and the size of adipocytes was also gradually increased with treatment time (Fig. 1c-d and Table 4).

mRNA expression of metabolism-related genes in liver and fat tissue

The mRNA expression level of Pgcla in liver showed significantly decreased in three and nine months HFSD treatments $(p<0.05$ and $p<0.001$ respectively), but no significant decrease in the fifth-month's treatment (Fig. 2). The mRNA levels of Insr gene in HFSD mice also showed a decreasing trend. However, HFSD treatments led to an up-regulation of Glut2 and Gck mRNA level after five months (increased to $9.71 \pm 0.91$ and $2.38 \pm 0.41$ respectively) (Fig. 2b), even both of them had still a higher content in HFSD mice than that in CON mice after nine months.

The mRNA expression patterns of Leptin, Insr, Pgcla and Glut4 in fat tissue were also carried out, the results were shown in Figure 2d-f. The Insr expression pattern showed a slightly decreasing in HFSD mice without significant difference among the treatment process. In contrast with the steady decline of Pgcla with time, Glut4 existed the most obvious decreasing tendency after five months' treatment; however, it presented no significant difference during ninth-month (Fig. 2f). On the contrary, the Leptin expression levels were increased significantly and had a gradual increasing tendency compared with those in $\mathrm{CON}$ mice.

\section{Methylation of Glut2, Glut4 and Leptin promoter DNA in} liver and fat tissue

Three genes of Glut2, Glut4 and Leptin that exhibited remarkable changes of mRNA expression at liver and/or fat tissue were selected to investigate the changes of methylation on $\mathrm{CpG}$ island in promoter DNA. There were four $\mathrm{CpG}$ sites, located on $-321 \mathrm{bp},-246 \mathrm{bp},-158 \mathrm{bp}$ and -140 bp in Glut2 promoter DNA respectively (Fig. S1a). It showed that all non-methylated cytosine was completely converted to thymine, and almost no background noise was observed in the sequencing results (Fig. S1b), indicating that they were no significant difference of 
DNA methylation levels of Glut2 promoter in liver between HFSD and CON mice at different stages, but there was a slightly decreasing trend during middle-aged and aged among them (Fig. S1c-f).

The DNA methylation levels of Leptin and Glut4 promoter in fat tissue were also measured. Results suggested that the methylation levels of Leptin promoter in CON mice changed differently among the involved $\mathrm{CpG}$ sites (from $-294 \mathrm{bp}$ to $-51 \mathrm{bp}$, covered $18 \mathrm{CpG}$ sites) with time, particularly the -230 bp and -181 bp (to $35.43 \pm 2.85$; $60.79 \pm 1.91$, respectively), both of them showed significantly increased level during senescence phase compared to those of middle-aged period (data not shown). Inconsistent with this, the methylation levels of $-94 \mathrm{bp}$ and $-84 \mathrm{bp}$ in HFSD mice were significantly decreased compared to those of $\mathrm{CON}$ mice at three different ages $(p<0.05)$ (Fig. 3a-c). These changes did not occur among HFSD mice with time.
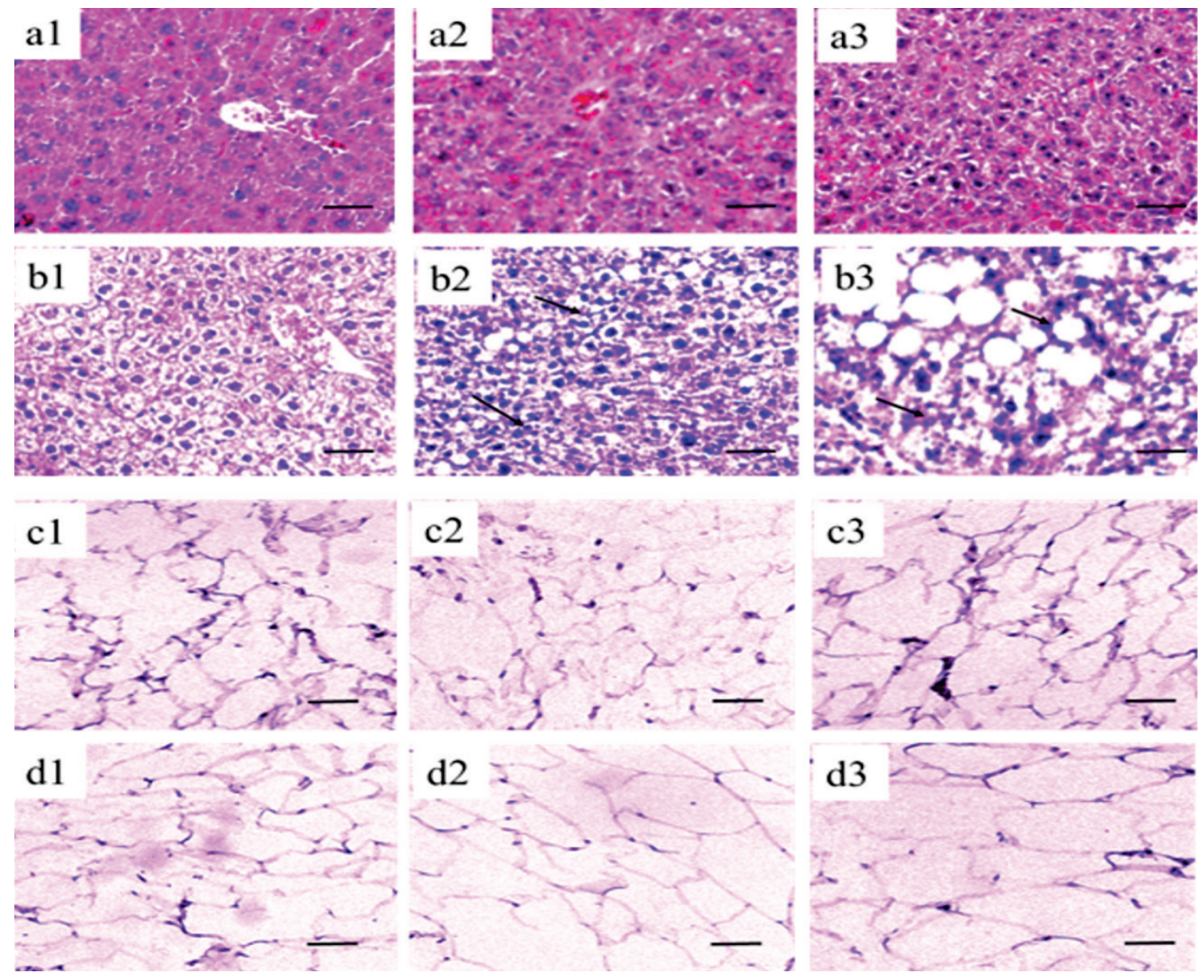

Fig. 1. Hepatic and adipose tissue hematoxylin and eosin (HE) staining following different treatment times. Representative images of HE-staining results of CON mice after three (a1), five (a2) and nine (a3) months respectively: there were clear and normal morphology, and it just few hepatocyte was edema. (b1) Representative images of HE-staining results of HFSD mice after three months: large amount of hepatocytes was edema. (b2) After five months, mostly hepatocytes of HFSD mice were edema even presented partly macrovesicular steatosis. (b3) After nine months, mostly hepatocytes had macrovesicular steatosis and partly cells were found the spotty necrosis, inflammatory cells infiltrating and the light liver fibrosis progression. HE-staining of adipose tissue after three $(\mathbf{c 1 / d \mathbf { 1 }})$, five $(\mathbf{c 2} / \mathbf{d 2})$ and nine $(\mathbf{c 3 / d 3})$ months in CON mice (c1-c3) and HFSD mice (d1-d3) respectively. Black arrow shown the macrovesicular steatosis area and spotty necrosis. $n=10$ per group. Scale bar is $100 \mu \mathrm{m}$.

With regard to those $\mathrm{CpG}$ sites (from $-436 \mathrm{bp}$ to $-146 \mathrm{bp}$, covered $11 \mathrm{CpG}$ sites) of Glut4 promoter, there no obvious correlation between mouse-growth/aging and methylation levels in CON mice was found (data not shown). The methylation levels in $-414 \mathrm{bp}$ in HFSD mice during middle-aged period showed an increase pattern (to 23.23 \pm 2.29 ), but did not reach significant level at aging state (Fig. 3d-f).

Expression level of DNMT1 protein in liver and fat tissue

Immunoblotting was carried out to measure the change of DNA methyltransferase 1 (DNMT1), which is 
responsible for maintenance DNA methylation, expression in liver and fat tissue with time combined with the dietary treatment. The results showed that DNMT1 protein level in liver had no significant difference between CON mice and HFSD mice at different ages (Fig. 4a), but the dramatically increased level of DNMT1 protein in fat tissue was found after five months' treatment (Fig. 4b).

Table 4. Quantitative analysis of hepatic steatosis and inflammation grading.

\begin{tabular}{|c|c|c|c|c|c|c|}
\hline \multirow{2}{*}{ Program } & \multicolumn{2}{|c|}{ Three-month } & \multicolumn{2}{|c|}{ Five-month } & \multicolumn{2}{|c|}{ Nine-month } \\
\hline & CON & HFSD & $\mathrm{CON}$ & HFSD & $\mathrm{CON}$ & HFSD \\
\hline Hepatic steatosis grading $(n / \%)$ & 0 & $1 *$ & 0 & $2^{*}$ & 0 & $3 *$ \\
\hline $0(<5 \%$, normal $)$ & $10 / 100 \%$ & 0 & $9 / 90 \%$ & 0 & $8 / 80 \%$ & 0 \\
\hline $1(5-5 \%)$ & 0 & $8 / 80 \%$ & $1 / 10 \%$ & 0 & $2 / 20 \%$ & 0 \\
\hline $2(26-50 \%)$ & 0 & $2 / 20 \%$ & 0 & $8 / 80 \%$ & 0 & 0 \\
\hline $3(51-75 \%)$ & 0 & 0 & 0 & $2 / 20 \%$ & 0 & $9 / 90 \%$ \\
\hline $4(>75 \%)$ & 0 & 0 & 0 & 0 & 0 & $1 / 10 \%$ \\
\hline \multicolumn{7}{|l|}{ Inflammatory infiltration } \\
\hline Cells/HPF & $2.1 \pm 1.6$ & $5.3 \pm 2.1$ & $3.0 \pm 1.4$ & $9.2 \pm 1.7^{*}$ & $3.1 \pm 1.1$ & $11.7 \pm 1.2^{*}$ \\
\hline \multicolumn{7}{|l|}{ Adipocyte } \\
\hline Cross-sectional area $\left(\mu m^{2}\right)$ & $1,400 \pm 100$ & $1,800 \pm 350$ & $1,650 \pm 150$ & $3,200 \pm 210^{*}$ & $2,000 \pm 230$ & $4,000 \pm 200^{*}$ \\
\hline
\end{tabular}

Note: HPF, high power field. The degree of steatosis was graded 0-4 based on the average percent of fat-accumulated hepatocytes per field of 10 random fields, grading $0 \leq 5 \%$ (normal liver), $1=5-25 \%, 2=26-50 \%, 3=51-75 \%, 4 \geq 75 \%$. Quantification of infiltrating inflammatory cells in liver and cross-sectional area of adipocyte were assessed in 10 different random fields. Values are presented as mean \pm S.E.M $(n=10){ }^{*} p<0.05$ vs. saline; vs. CON group at same age.
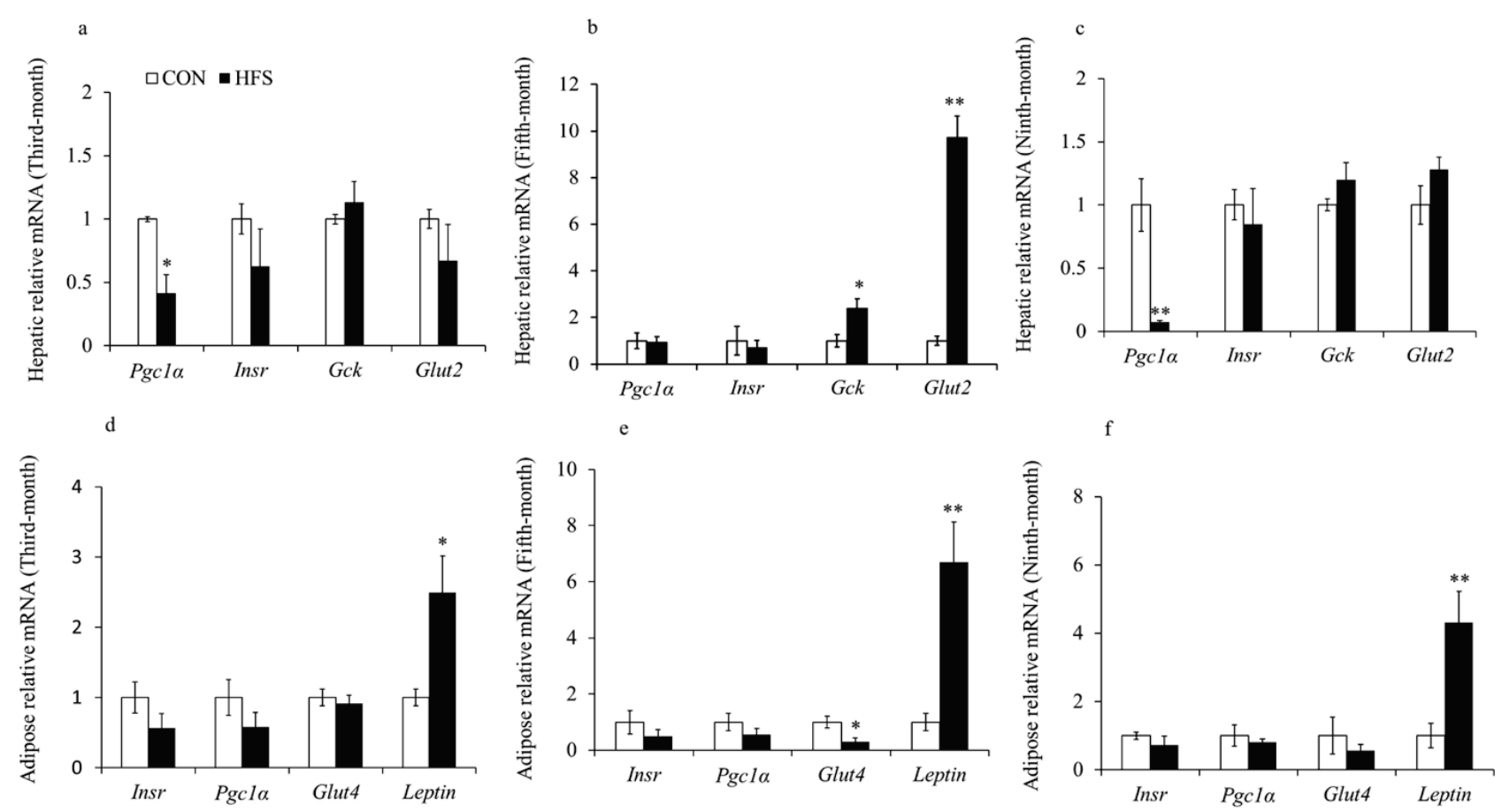

Fig. 2. Changes of genes relative expression (\%) of liver and fat tissue after dietary treatment within different times. Changes of genes expression in liver after three (a), five (b) and nine (c) months respectively, including Pgc1a (peroxisome proliferator-activated receptor gamma coactivator 1-alpha), Insr (insulin receptor), Gck (glucokinase) and G/ut2 (glucose transport protein 2). Changes of genes expression in fat tissue after three (d), five (e) and nine (f) months respectively, including Pgc1a, Insr, Leptin and G/ut4 (glucose transport protein 4). Values are presented as mean \pm S.E.M $(n=6-8) . * p<0.05$ and $* * p<0.001$ vs. CON group at same age. 

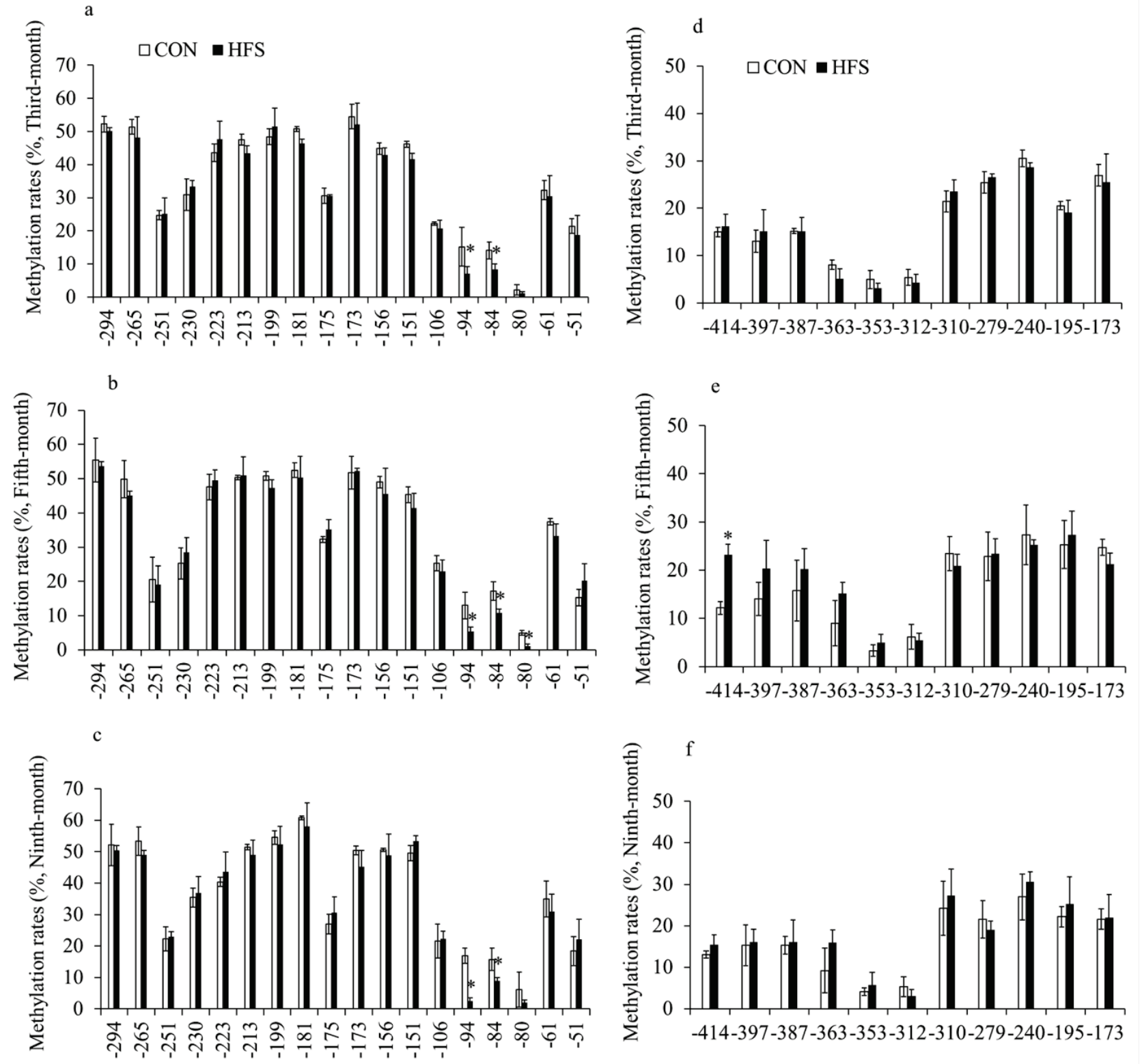

Fig. 3. Methylation rates (\%) of Leptin and G/ut4 promoter after dietary treatment. Methylation levels of Leptin promoter after dietary treatment for three (a), five (b) and nine (c) months respectively in fat tissue. Methylation levels of G/ut4 promoter after dietary treatment for three (d), five (e) and nine (f) months respectively in liver. Values are presented as mean \pm S.E.M. $(\mathrm{n}=6){ }^{*}{ }^{*} p<0.05$, vs. the CON group at same age.

\section{Discussion}

The dramatic increase in the epidemic of obesity worldwide has become a serious threat to human health and the quality of life, which is also a major risk factor in the development of common disease, like cardiovascular disease, nonalcoholic fatty liver, atherogenic dyslipidemia, hypertension and type 2 diabetes and so forth. The changes of dietary structure may cause the imbalance between energy intake and expenditure and therefore bring on metabolism disorder so as to become overweight and obesity (Mello et al. 2014). Our results showed that the high-fat and high-sucrose diet (HFSD) could induce obesity and even the super-obesity with time (Table 2). Mice with super-obesity presented the body weight increased 2 folds more than normal mice, but did not mimic diabetes. This is a novel finding, which is differed from the results previously reported (Surwit $e t$ al. 1988). The obesity parameters included the body weight, Lee's index and fat/body mass (\%) of HFSD group were significantly increased compared to those of CON group after three months $(p<0.001)$, and also the significant difference remained to the long term (9 months) (Table 2 and Table 3). And the serum leptin 
concentration level, the cholesterol and triglycerides concentration of HFSD groups were significantly increased compared to those of $\mathrm{CON}$ groups with obese development. These results indicated that HFSD condition we employed was able to induce a stable adiposis in C57BL/6J mice, which agreed with researches have been reported by Mello et al. (2014). a
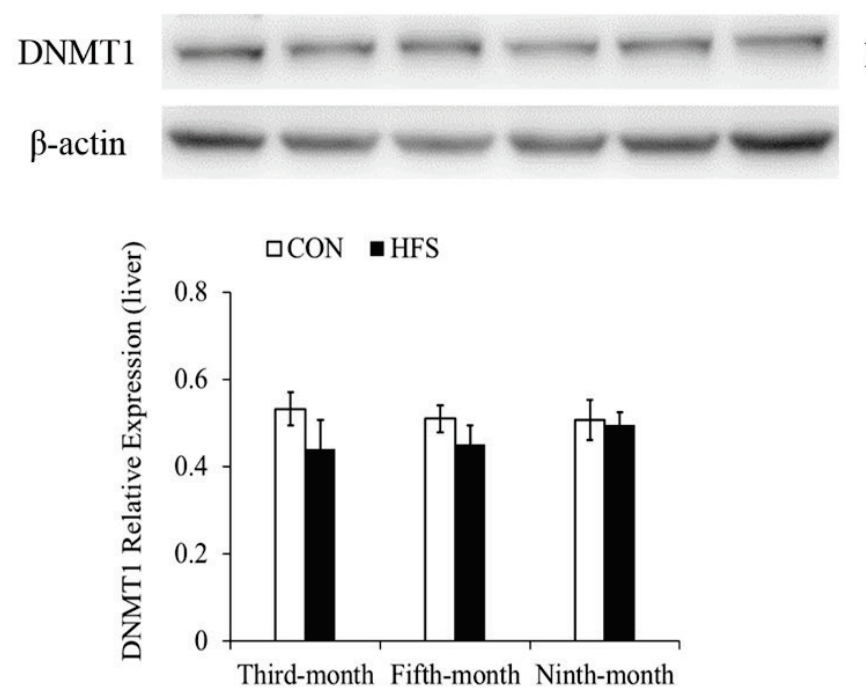

b
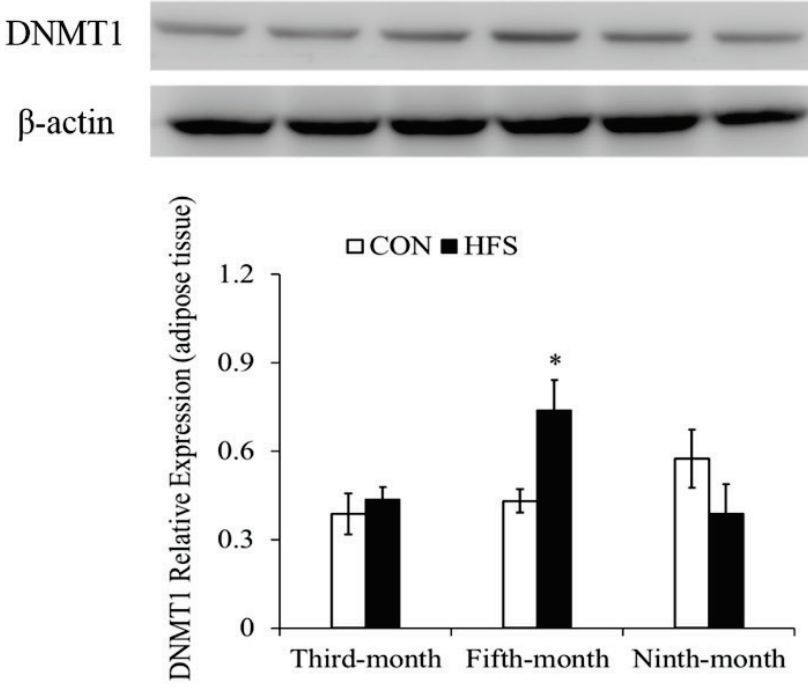

Fig. 4. DNMT1 protein levels in liver and fat tissue following dietary treatment within different times. (a) Changes of DNMT1 protein expression levels in liver after dietary treatment for three, five and nine months respectively. (b) Changes of DNMT1 protein expression in fat tissue after dietary treatment for three, five and nine months respectively. Values are presented as mean \pm S.E.M ( $n=4)$. $* p<0.05$, vs. the CON group at same age.

Except the changes on morphological adiposis, HFSD also induced a remarkable T2D like characteristics (Table 2) after diets treatment for five months, such as high level of fasting blood glucose, glycosylated hemoglobin (GHbAlc) and homeostasis model assessment HOMA-IR, lower HOMA- $\beta$ and HOMA-IS, indicating that the adiposis mice have been occurred a physiological and biochemical alteration in vivo, and have become impairments to the regulation of glucose homeostasis which then have the potential be the acceptable reservists of type 2 diabetes, even exhibit certain pathological changes. The HE staining of liver and fat tissue in HFSD mice confirmed such results (Fig. 1 and Table 4), which showed the severity degree of pathological damage, severe fatty liver and macrovesicular steatosis, inflammatory cell infiltrating, and significantly increased cross-sectional area of lipocytes, and the size of lipocytes (Fig. 1 and Table 4). Recently several evidences have shown that epigenetic modifications on metabolism related genes induced by nutrition factor plays important rule in adiposis development (Lavebratt et al. 2012). The diet adjustment and dietary structure could cause the epigenetic changes and promote cells reprogramming by regulating gene expression and therefore bring the physiological and biochemical alteration in vivo (Mello et al. 2014, Cheng et al. 2017).

As we all know, the increased Leptin expression relates with increasing fat mass, which proved that the increased adiposity contributed to high levels of Leptin. Chronic higher levels of insulin found in HFSD mice might be due to the impaired insulin sensitivity which produced by the lower levels of Glut4 expression at present study. It is generally agreed that physiological changes resulted from the expression changes of related genes, which usually associated with epigenetic modification in histone and gene promoter ( $\mathrm{Tu}$ et al. 2015). The results in present study suggested that genes expression of Leptin and Glut4 in fat tissue exhibited contrary transition trends with the DNA methylation patterns, the DNMT1 protein level further strengthened the evidence at middle-aged period (Fig. 2-4 and Fig. S1). The age combined with HFSD exaggerate the influence on DNA methylation, the HFSD is sufficient to mediate the impact on DNA methylation pattern of Leptin and Glut4 after five months. This study may provide 
a mechanism that the changes of methylation, especially the changes of aberrant methylation, by diet adjustments exaggerate the adiposis development. This agreed with the result has been reported previously (Seki et al. 2012, Cheng et al. 2017). The aberrant methylation of promoter regions generally effected the binding of transcription factors, which further regulated the genes expression. The methylation analysis of Glut4 and Leptin are the first time to carry out by looking over multiple time points in a HFSD model. In addition, the changes of methylation of non- $\mathrm{CpG}$ island and non-promoter region or even the genome-wide also play a vital role in regulating genes expression (Cordero et al. 2011, Barrès et al. 2009).

Because the specific mechanisms between methylation and gene expression are not exactly clear yet, further studies should be conducted to clarify the correlation between environment changes (in particular the diet style) and individual physiological reaction.

\section{Conclusions}

The HFSD in present research conditions was able to induce a stable adiposis in $\mathrm{C} 57 \mathrm{BL} / 6 \mathrm{~J}$ mice and alter the expression status of metabolism related genes (Leptin, Glut4 and Glut2). The higher level of DNMT1 induced by HFSD in fat tissue might play the most important role in changes of methylation pattern on Glut4 and Leptin genes, and which might be one of the molecular mechanisms for the adiposis development in C57BL/6J mice.

\section{Conflict of Interest}

There is no conflict of interest.

\section{References}

BARRÈS R, OSLER ME, YAN J, RUNE A, FRITZ T, CAIDAHL K, KROOK A, ZIERATH JR: Non-CpG methylation of the PGC-1 $\alpha$ promoter through DNMT3B controls mitochondrial density. Cell Metab 10: 189-198, 2009.

BASTARD JP, MAACHI M, LAGATHU C, KIM MJ, CARON M, VIDAL H, CAPEAU J, FEVE B: Recent advances in the relationship between obesity, inflammation, and insulin resistance. Eur Cytokine Netw 17: 4-12, 2006.

BERNARDIS LL, PATTERSON BD: Correlation between 'lee index' and carcass fat content in weanling and adult female rats with hypothalamic lesions. J Endocrinol 40: 527-528, 1968.

BRUNT EM, JANNEY CG, DI BISCEGLIE AM, NEUSCHWANDER-TETRI BA, BACON BR: Nonalcoholic steatohepatitis: a proposal for grading and staging the histological lesions. Am J Gastroenterol 94: 2467-2474, 1999.

BUSCHEMEYER WC 3RD, FREEDLAND SJ: Obesity and prostate cancer: epidemiology and clinical implications. Eur Urol 52: 331-343, 2007.

CHEN HC, FARESE RV JR: Determination of adipocyte size by computer image analysis. J Lipid Res 43: 986-989, 2002.

CHENG CW, VILLANI V, BUONO R, WEI M, KUMAR S, YILMAZ OH, COHEN P, SNEDDON JB, PERIN L, LONGO VD: Fasting-mimicking diet promotes Ngn3-driven $\beta$-cell regeneration to reverse diabetes. Cell 168: 775-788, 2017.

CORDERO P, CAMPION J, MILAGRO FI, GOYENECHEA E, STEEMBURGO T, JAVIERRE BM, MARTINEZ JA: Leptin and TNF- $\alpha$ promoter methylation levels measured by MSP could predict the response to a low-calorie diet. J Physiol Biochem 67: 463-470, 2011.

DUAN H, MA B, MA X, WANG H, NI Z, WANG B, LI X, JIANG P, UMAR M, LI M: Anti-diabetic activity of recombinant irisin in STZ-induced insulin-deficient diabetic mice. Int J Biol Macromol 84: 457-463, 2016.

FRIEDMAN JM, HALAAS JL: Leptin and the regulation of body weight in mammals. Nature 395: 763-770, 1998.

GINZINGER DG: Gene quantification using real-time quantitative PCR: an emerging technology hits the mainstream. Exp Hematol 30: 503-512, 2002.

HALAAS JL, BOOZER C, BLAIRWEST J, FIDAHUSEIN N, DENTON DA, FRIEDMAN JM: Physiological response to long-term peripheral and central leptin infusion in lean and obese mice. Proc Natl Acad Sci USA 94: 8878-8883, 1997. 
HARING SJ, HARRIS RB: The relation between dietary fructose, dietary fat and leptin responsiveness in rats. Physiol Behav 104: 914-922, 2011.

IP BC, LIU C, SMITH DE, AUSMAN LM, WANG XD: High-refined-carbohydrate and high-fat diets induce comparable hepatic tumorigenesis in male mice. J Nutr 144: 647-653, 2014.

ISOMAA B, ALMGREN P, TUOMI T, FORSÉN B, LAHTI K, NISSÉN M, TASKINEN MR, GROOP L: Cardiovascular morbidity and mortality associated with the metabolic syndrome. Diabetes Care 24: 683-689, 2001.

IWASE T, SANGAI T, NAGASHIMA T, SAKAKIBARA M, SAKAKIBARA J, HAYAMA S, ISHIGAMI E, MASUDA T, MIYAZAKI M: Impact of body fat distribution on neoadjuvant chemotherapy outcomes in advanced breast cancer patients. Cancer Med 5: 41-48, 2016.

JAMES PT, RIGBY N, LEACH R, INTERNATIONAL OBESITY TASK FORCE: The obesity epidemic, metabolic syndrome and future prevention strategies. Eur J Cardiovasc Prev Rehabil 11: 3-8, 2004.

JIN B, SEONG JK, RYU DY: Tissue-specific and de novo promoter methylation of the mouse glucose transporter 2. Biol Pharm Bull 28: 2054-2057, 2005.

LAVEBRATT C, ALMGREN M, EKSTRÖM TJ: Epigenetic regulation in obesity. Int J Obes (Lond) 36: 757-765, 2012.

LEWIN J, SCHMITT AO, ADORJÁN P, HILDMANN T, PIEPENBROCK C: Quantitative DNA methylation analysis based on four-dye trace data from direct sequencing of PCR amplificates. Bioinformatics 20: 3005-3012, 2004.

LILLYCROP KA, PHILLIPS ES, TORRENS C, HANSON MA, JACKSON AA, BURDGE GC: Feeding pregnant rats, a protein-restricted diet persistently alters the methylation of specific cytosines in the hepatic PPAR $\alpha$ promoter of the offspring. Br J Nutr 100: 278-282, 2008.

LIM SS, VOS T, FLAXMAN AD, DANAEI G, SHIBUYA K, ADAIR-ROHANI H, AMANN M, ANDERSON HR, ANDREWS KG, ARYEE M, ATKINSON C, BACCHUS LJ, BAHALIM AN, BALAKRISHNAN K, BALMES J, BARKER-COLLO S, BAXTER A, BELL ML, BLORE JD, BLYTH F, ET AL.: A comparative risk assessment of burden of disease and injury attributable to 67 risk factors and risk factor clusters in 21 regions, 1990-2010: a systematic analysis for the Global Burden of Disease Study 2010. Lancet 380: 2224-2260, 2012.

LIU ZJ, BIAN J, ZHAO YL, ZHANG X, ZOU N, LI D: Lentiviral vector-mediated knockdown of SOCS3 in the hypothalamus protects against the development of diet-induced obesity in rats. Diabetes Obes Metab 13: 885-892, 2011.

MALIK VS, WILLETT WC, HU FB: Global obesity: trends, risk factors and policy implications. Nat Rev Endocrinol 9: 13-27, 2013.

MCGOWAN PO, SASAKI A, D'ALESSIO AC, DYMOV S, LABONTÉ B, SZYF M, TURECKI G, MEANEY MJ: Epigenetic regulation of the glucocorticoid receptor in human brain associates with childhood abuse. Nat Neurosci 12: 342-348, 2009.

MELLO VD, PULKKINEN L, LALLI M, KOLEHMAINEN M, PIHLAJAMÄKI J, UUSITUPA M: DNA methylation in obesity and type 2 diabetes. Ann Med 46: 103-113, 2014.

RIDKER PM, MORROW DA: C-reactive protein, inflammation, and coronary risk. Cardiol Clin 21: 315-325, 2003.

RAMACHANDRAPPA S, FAROOQI IS: Genetic approaches to understanding human obesity. J Clin Invest 121: 2080-2086, 2011.

SCARPACE PJ, MATHENY M, TÜMER N, CHENG KY, ZHANG Y: Leptin resistance exacerbates diet-induced obesity and is associated with diminished maximal leptin signalling capacity in rats. Diabetologia 48 : 1075-1083, 2005.

SEKI Y, WILLIAMS L, VUGUIN PM, CHARRON MJ: Minireview: epigenetic programming of diabetes and obesity: animal models. Endocrinology 153: 1031-1038, 2012.

SHULMAN GI: Cellular mechanisms of insulin resistance. J Clin Invest 106: 171-176, 2000.

STARLEY BQ, CALCAGNO CJ, HARRISON SA: Nonalcoholic fatty liver disease and hepatocellular carcinoma: a weighty connection. Hepatology 51: 1820-1832, 2010.

SURWIT RS, KUHN CM, COCHRANE C, MCCUBBIN JA, FEINGLOS MN: Diet-induced type II diabetes in C57BL/6J mice. Diabetes 37: 1163-1167, 1988. 
TU P, LI X, MA B, DUAN H, ZHANG Y, WU R, NI Z, JIANG P, WANG H, LI M, ZHU J, LI M: Liver histone H3 methylation and acetylation may associate with type 2 diabetes development. J Physiol Biochem 71: 89-98, 2015.

WALLACE TM, LEVY JC, MATTHEWS DR: Use and abuse of HOMA modeling. Diabetes Care 27: 1487-1495, 2004.

WOLEVER TM, JENKINS DJ, JENKINS AL, JOSSE RG: The glycemic index: methodology and clinical implications. Am J Clin Nutr 54: 846-854, 1991.

XU X, SU S, BARNES VA, MIGUEL CD, POLLOCK J, OWNBY D, SHI H, ZHU H, SNIEDER H, WANG X: A genome-wide methylation study on obesity: differential variability and differential methylation. Epigenetics 8: 522-533, 2013. 